\title{
SISTEM PENENTUAN GUDANG BERAS BERBASIS IOT MENGGUNAKAN METODE SAW PADA PLATFORM THINGSBOARD
}

\author{
Timbo Faritcan Parlaungan Siallagan ${ }^{* 1}$, Agus Sudrajat ${ }^{\# 2}$ \\ Program Studi Teknik Komputer dan Jaringan, STMIK Subang ${ }^{* 1}$ \\ Program Studi Teknik Informatika, STMIK Subang ${ }^{\# 2}$ \\ Email : timbo.siallagan@yahoo.com ${ }^{* 1}$, agussudrajat@gmail.com ${ }^{\# 2}$
}

\begin{abstract}
ABSTRAK
Sistem Penentuan Tempat Penyimpanan Gudang Beras, Kasomalamg merupakan suatu system yang dapat membantu petugas dalam pemeliharaan Tempat Penyimpanan Beras. Terdapat beberapa faktor yang dapat mempengaruhi ketahanan kualitas beras yaitu, suhu, kelembaban, dan debu. Yang dapat mempengaruhi kualitas beras menjadi cepat berjamur dan berkutu.

Tujuan dari penelitian ini adalah untuk mengetahui ketahanan tempat penyimpanan beras dengan kualitas suhu, kelembaban, serta kebersihan ruangan dengan nilai yang berbeda. Data yang dihitung Menggunakan menggunakan Mikrokontroller dengan Sensor DHT11 untuk membaca parameter suhu dan parameter kelembaban serta sensor debu yang dapat membaca ketebalan debu dengan berbasis Internet of Things. Kemudian data di olah menggunakan perangkingan dengan Metode Simple Addictive Weight (SAW) untuk mengetahui tempat penyimpanan beras dengan hasil perhitungan tertinggi sebagai tempat penyimpanan beras terbaik.
\end{abstract}

Kata Kunci : Gudang Penyimpanan, Internet of Thing (IoT), Simple Additive Weight (SAW)

\begin{abstract}
Determination of Rice Warehouse Storage System, Kasomalamg is a system that can assist officers in maintaining Rice Storage. There are several factors that can affect the quality of rice security, namely, temperature, humidity, and dust. Which can affect the quality of rice becomes moldy and fast ticking.

The purpose of this study is to determine the durability of rice storage with the quality of temperature, humidity, and cleanliness of the room with different values. Data calculated using the Microcontroller with DHT11 Sensor to read temperature parameters and humidity parameters as well as dust sensors that can read the thickness of the dust based on the Internet of Things. Then the data is processed using the ranking method with Simple Addictive Weight (SAW) to determine the storage of rice with the highest calculation results as the best rice storage.
\end{abstract}

\section{Kata Kunci : Internet of Thing (IoT), Metode Weighted Product, Warehouse}

\section{Pendahuluan}

\section{1 LatarBelakang}

Indonesia merupakan negara agraris, dengan luas lahan pertanian berupa sawah seluas 8.087.393 ha. Produksi padi pada tahun 2015 di Indonesia diperkirakan mencapai 75,40 juta ton gabah kering giling (GKG). Beras merupakanhasil pertanian yang merupakan makanan pokok dan sumber nutrisi penting dalam struktur pangan mayoritas penduduk Indonesia. Berdasarkan data data dari Badan Pusat Statistik (BPS) tahun 2015, rata-rata konsumsi beras terhadap konsumsi tanaman sumber karbohidrat secara keseluruhan mencapai 89,20 persen. Besarnya konsumsi beras di Indonesia dan banyaknya produksi beras membutuhkan ruang penyimpanan seperti gudang Bulog. Proses penyimpanan perlu diperhatikan untuk mempertahankan kualitas beras agar layak dikonsumsi. [1]

Menurut penelitian yang dilakukan oleh (Ratnawati, 2013), beras mengalami penurunan kualitas yang dipengaruhi oleh suhu dan kelembaban selama penyimpanan. Dalam penelitian tersebut digunakan tiga jenis beras yaitu beras yang mendekati SNI mutu III , memenuhi SNI mutu IV, dan beras yang tidak memenuhi standar mutu SNI. Beras disimpan dengan suhu relatif penyimpanan $29-32^{\circ} \mathrm{C}$ dan kelembaban relatif $65-95 \%$. Hasilnya ketiga jenis beras tersebut mengalami penurunan kualitas, baik dari sisi peningkatan jumlah butir patah, butir menir, maupun butir menguning. Selain itu, munculnya kutu beras dengan kecepatan pertumbuhan 3 ekor/100g 
beras/minggu. [2]

Hal ini menunjukkan bahwa beras dengan mutu yang baik tetap akan mengalami penurunan kualitas yang dipengaruhi oleh suhu dan kelembaban saat penyimpanan. Oleh karena itu, pengaturan suhu dan kelembaban penyimpanan beras sangat penting untuk menjaga kualitas beras. Pengaturan suhu dan kelembaban tentunya sulit dilakukan secara manual, terlebih penyimpanan beras dalam kapasitas besar seperti di gudang Bulog. Perubahan suhu ruangan yang terjadi secara acak sehinga tidak dapat diprediksi. Oleh karena itu, diperlukan suatu sistem yang dapat mengontrol suhu dan kelembaban gudang secara otomatis. Smart Warehouse dengan menggunakan perangkat cerdas tertanam/Internet of Things (IoT) dapat menjadi solusi yakni dengan algoritma yang ditanamkan pada mikrokontroler, aktuator dapat mengeksekusi perintah sesuai dengan hasil pengukuran atau pendeteksian oleh sensor. (Septama \& dkk, 2018)

Dalam suatu perusahaan besar, gudang mempunyai artiyang sangat penting untuk aliran barang dalam perusahaan tersebut. Gudang adalah sebuah bangunan atau ruangan yang digunakan sebagai tempat pengimpanan semua bahan di pabrik ataupun perusahaan. Didalam gudang terdapat tiga aktivitas utama yaitu proses penerimaan barang, proses penyimpanan barang, dan proses pendistribusian barang. Aktivitas di dalam gudang tersebut yang dinamakan dengan pergudangan. Funsi utama gudang adalah tempat penyimpanan bahan-bahan mentah (raw material), barang setengah jadi (intermediate goods), maupun produk yang telah jadi (finish goods). [3]

Gudang juga mempunyai peran penting guna mendukung keberhasilan perusahaan dalam mencapai tujuannya, hal tersebut harus didukung dengan aktivitas pergudangan yang baik, dimulai dari poses penerimaan barang, proses penyimpanan barang, perawatan barang, pencatatan persediaan, sampai dengan pengeluaran barang untuk dikirim kepada konsumen. Selain itu perlu juga ditunjang dengan adanya sistem informasi pergudangan, yang berfungsi untuk membantu pengelolaan barang-barang di dalam gudang. Dengan pengelolaan informasi yang teratur, diharapkan kegiatan yang berlangsung di dalam gudang dapat berjalan dengan baik. Hal ini menyebabkan kebutuhan akan adanya gudang disuatu perusahaan sangat penting adanya [4].

Dalam penelitian (Yuliant \& dkk, 2015) dengan judul Aplikasi Pemantau Suhu dan Kelembapan Pada Indikator Bayi Berbasis Internet menyampaikan bahwa Bayi premature akan mudah mengalami kedinginan, sehingga dibutuhkan suatu perangkat pelinfung tertentu yang dapat mengondisikan suhu dan kelembapan.

Dalam penelitiannya (Muktiawan \& Nurfina, 2018) juga meyampaikan hasil penelitiannya dengan judul Sistem Monitoring Penyimpanan Kebutuhan Pokok Berbasis Internet Of Things (IoT) bahwa system monitoring kebutuhan pokok merupakan sebuah system yang digunakan untuk melihat ketersediaan kebutuhan pokok. Pentingnya monitoring kebutuhan pokok adalah untuk mengetahui jumlah ketersediaan bahan pokok setiap saatm sehingga apabikla kebutuhan pokok berkurang atau habis pengguna dapat memenuhi kebutuhan pokok tersebut.

Hasil penelitian (Septama \& dkk, 2018) Dengan judul Sistem Pemantauan Kontrol Otomatis Suhu serta Kelembaban Gudang menunjukkan bahwa dengan adanya Internet Of Things (IOT) pemantauan suhu dan kelembaban dapat dipantau secara real-time melalui website. Dalam penelitiannya (Ratnawati, 2013) Menyampaikan bahwa penyusutan kualitas dan kuantitas beras selama penyimpanannya disebabkan oleh perubahan fisik, kimia dan biologi.

Hasil penelitian Prihandoko dkk. Dengan judul Analysis of Disease Data in Indonesia by Using SAW and AHP Decision Support Methods menunjukkan bahwa kedua metode tersebut dapat digunakan untuk mencari tahu provinsi dengan yang Jumlah penyakit terbanyak dan implementasi AHP dan SAW menghasilkan pemeringkatan yang berbeda dari provinsi yang memiliki jumlah kasus pada tiap-tiap penyakit tersebut. (Prihandoko \& dkk, 2016)

\subsection{Identifikasi Masalah}

Identifikasi permasalahan yang diperoleh dari latar belakang sebagai berikut:

1. Belum optimalnya penggunaan penyimpanan beras dalam suatu tempat penyimpanan.

2. Belum adanya penelitian yang mendalam mengenai system penentuan tempat penyimpanan beras dengan pembersihan secara real time.

3. Upaya awal pemanfaatan dalam tempat penyimpanan beras agar kualitas beras dan ketahan beras terhindar dari jamur ataupun kutu.

\subsection{Tujuan}

1. Membuat suatu alat prototype yang dapat digunakan untuk memonitoring tempat penyimpanan beras. 
2. Merancang suatu alat prototype system monitoring suhu, kelembaban, dan debu pada tempat penyimpanan beras secara realtime.

3. Menerapkan teknologi Internet of Things untuk memonitoring suhu, kelembaban, dan debu secara realtime.

\subsection{Manfaaat}

Manfaat yang dari penelitian ini antara lain:

1. Agar lebih mudah saat memonitoring penyimpanan beras dalam suatu ruangan tanpa harus mengecek langsung ke lokasi dan dapat di pantau secara real-time melalui website.

2. Hasil dari penelitian ini dapat dijadikan referensi atau masukan untuk pengembangan system otomatiasi menggunakan IoT.

\subsection{Metodologi Penelitian}

Metode penelitian yang digunakan penulis sebagai berikut:

1. Studi Literatur

Mempelajari dan mengumpulkan data berupa data yang dihasilkan oleh sensor kemudian diolah menggunakan metode Simple Addictive Weight (SAW) sehingga menghasilkan peringkat tiap lokasi yang diuji, metode ini akan digunakan untuk proses Sistem Pendukung Keputusan.

2. Dokumentasi

Dilakukan untuk mencari dokumen - dokumen dan mengumpulkan data-data apa saja yang menunjang dalam penyusunan tugas akhir.

3. Analisa Dan Perancangan Sistem

Analisa dan perancangan sistem ini dilakukan untuk mengkaji hasil studi literatur, hasil survei lapangan, dan menganalis yang dibutuhkan untuk melakukan perancangan awal alat dan sistem yang akan dibuat, sehingga akan dihasilkan desain antarmuka dan proses untuk diimplementasikan.

4. Pembuatan Sistem

Tahap ini mengimplementasikan Iot (Internet Of Thing) untuk mendistribusikan sumber air bersih dengan merancang sebuah sistem penentuan gudang beras berbasis Iot (Internet Of Thing) dengan menggunakan metode Simple Addictive Weight(SAW) dan platform Thingsboard.

5. Uji Coba dan Evaluasi Sistem

Pada tahap ini alat dan sistem yang telah dibuat ini akan dilakukan beberapa skenario uji coba dan dievaluasi untuk kelayakan pemakaian alat dan sistem ini. Pada tahap ini akan di uji coba atau dievaluasi alat dan system yang telah dibuat untuk melihat kesesuaian rancangan yang diinginkan.

\section{Pustaka}

\subsection{Simple Addictive Weighting (SAW)}

Proses penilaian menentukan penyimpanan gudang beras dalam suatu ruangan memang sangatlah tidak mudah. Rentannya jamur dan kutu mempercepat kerusakan pada kualitas beras, sehingga dibutuhkan tempat dengan lokasi yang cocok. Dalam penentuannya ada beberapa kriteria yang harus di perhatikan oleh suatu tempat atau lokasi tertentu. Selain untuk mengevaluasi hasil penyimpanan yang baik, proses penentuan ruangan pun harus di perhatikan dari segi kelembaban dan suhu. Hal ini dilakukan agar mendorong suatu hasil beras dengan kualitas yang bagus dengan kapasitas waktu yang lumayan cukup lama. Suapaya dalam pengambilan keputusan dapat dilakukan secara efektif, salah satu alternatifnya adalah dengan menggunakan sebuah system. System yang berbasis web memungkinkan seorang petugas gudang dapat melakukan proses penentuan gudang beras kapanpun dan dimanapun.

Dalam penelitiannya (Rafika \& dkk, 2018) menyampaikan bahwa sudah banyak metode pengambilan keputusan yang dipakai untuk menyelesaikan masalah, salah satunya adalah metode Simple Addictive Weighting. metode Simple Addictive Weighting (SAW) merupakan metode yang memiliki konsep dasar mencari penjumlahan berbobot dari rating pada setiap alternatif pada semua atribut. Kelebihan metode SAW jika dibandingkan dengan metode yang lain adalah bahwa metode SAW mempunyai kemampuan untuk melakukan penilaian lebih tepan karena didasarkan pada nilai kriteria dan bobot pada tingkat kepentingan yang di butuhkan. Model dari sebuah pengambilan keputusan digunakan untuk mengevaluasi, melakukan pemeringkatan, dan memilih atlernatif yang tepat dari beberapa alternatif lainnya. [5]

Dalam penelitiannya (Sinaga \& dkk, 2016) Menyampaikan bahwa Simple Addictive Weighting (SAW) yang juga dinekal sebagai kombinasi linear tertimbang atau metode penilaian adalah sederhana 
dan paling sering menggunakan teknik keputusan multi atribut. Metode itu didasarkan pada rata-rata tertimbang. Skoer evaluasi dihitung untuk setiap alternatif dengan mengalikan skala nilai yang diberikan ke alternatif atribut itu dengan bobot kepentingan relatif langsung ditugaskan oleh pengambil keputusan diikuti dengan menjumlahkan produk untuk semua kriteria. Itu keuntungan dari metode ini adalah bahwa linear proporsional transformasi data mentah yang berarti relative urutan besarnya skor standar tetap sama.

Langkah-langkah kinerja metode SAW atau tertimbang yaitu (Sunarti \& dkk, 2018):

a) Tentukan kriteria yang akan digunakan sebagai referensi dalam pengmabilan keputusan, yaitu $\mathrm{Cj}$.

b) Memberikan nilai setiap alternative Ai pada kriteria yang sudah ditentukan, di mana nilai itu diperoleh berdasarkan pada nilai crips.

c) Tentukan nilai peringkat kesesuaian setiap alternatif pada setiap kriteria kemudian ditetapkan ke dalam angka fuzzy setelag itu dikonversikan ke integer crips.

d) Tentukan bobot referensi atau kepentingan (W) pada setiap kriteria.

e) Membuat matriks keputusan (X) yang dibentuk dari tabel memberi peringkat kesesuaian salah satu alternatif pada setiap kriteria.

f) Apakah matriks keputusan dengan langkah-langkah normalisasi melakukan perhitungan nilai normalisasi performance rating (rij) dari alternatif $\mathrm{Ai}$ pada kriteria $\mathrm{Cj}$.

$\mathrm{Rij}=$

$$
=\frac{x i j}{\operatorname{Max}(x i j)}
$$

$$
=\frac{x i j}{\operatorname{Min}(x i j)}
$$

Dimana :

$\mathrm{Rij}=$ peringkat kinerja normalisasi Maxij = nilai maksimum setiap baris dan kolom

Minij = nilai minim setiap baris dan kolom Xij = baris dan kolom baris dan matriks

g) Hasil nilai ternormalisasi dari penelitian kinerja (rij) yang membentuk matriks ternormalisasi (R) dan hasil akhir (Vi) diperoleh nilai preferensi dari penjumlahan normaliasasi unsur kerja matriks perkalian dengan preferensi tertimbang (W) elemen matriks kolom $(\mathrm{W})$ yang sesuai.

Deskripsi :

$$
V i=\sum_{j=1}^{n} \mathrm{j}=1 \mathrm{Wj} . \mathrm{rij}
$$

$\mathrm{Vi}=$ Memberi peringkat untuk setiap alternative

$\mathrm{Wj}=$ nilai peringkat tertimbang (dari setiap alternatif)

$\mathrm{Rij}=$ nilai peringkat kinerja normalisasi nilai Vi yang lebih besar menunjukkan bahwa alternatif Ai lebih dipilih.

\subsection{Beras}

Beras merupakan makanan pokok di tidak kurang 26 negara padat penduduk (China, India, Indonesia, Pakistan, Bangladesh, Malaysia, Thailand, Vietnam), atau lebih separuh penduduk dunia. Di Indonesia, masalah beras erat kaitannya dengan masalah budaya, social dan ekonomi bangsa. Keeratan hubungan antara padi (beras) dengan manusia tercermin dari berbagai kepercayaan penduduk, antara lain melalui hikayat Dewi Sri. Dalam bidang ekonomi, beras sering digunakan sebagai indeks kestabilan ekonomi nasional. Padi (Oryza sativa L.) merupakan famili graminae dan genus Oryza.

Padi jenis lain yaitu Oryza glaberrima, merupakan tanaman liar, tetapi bila dibudidayakan tidak dapat menghasilkan beras seperti Oryza sativa L. Padi ditanam lebih dari 100 negara dari semua benua kecuali antartika. Padi ditanam pada daerah 53 o LU-40 o LS sampai ketinggian $3000 \mathrm{~m}$ di atas permukaan laut. Tanaman padi (Oryza sativa) dapat dibedakan atas tiga ras, yaitu Javanika, Japonika dan Indika. Jenis Indika mempunyai butir padi berbentuk lonjong panjang dengan rasa nasi pera, sedangkan pada jenis Japonika, butirnya pendek bulat, dengan rasa nasi pulen dan lengket. Beras yang ada di Indonesia secara umum dikategorikan atas varietas bulu dengan ciri bentuk butiran agak bulat sampai bulat dan varietas cere dengan ciri bentuk butiran lonjong sampai sedang.

Indica lebih pendek masa tanamya, tahan kekurangan air, dipanen sekaligus karena butir padi mudah terlepas dari malainya sehingga mudah tercecer. Sedangkan japonica lebih lama masa tanamnya, tanaman lebih tinggi, dipanen satu per satu karena butir padi melekat kuat pada malainya. Penanaman beras di Indonesia juga sering didasarkan atas daerah produksinya, misalnya beras Rojolele dan Cianjur dari Jawa 
Barat, Siarias dari Sumatra Utara, Solok dari Sumatera Barat dan beras Empat Bulan dari Sumatera Selatan.

Sebagai bahan pangan pokok bagi sekitar $90 \%$ penduduk Indonesia, beras menyumbang antara $40-$ $80 \%$ kalori dan $45-55 \%$ protein. Sumbangan beras dalam mengisi kebutuhan gizi tersebut makin besar pada lapisan penduduk yang berpenghasilan rendah. Mengingat demikian pentingnya beras dalam kehidupan bangsa Indonesia, maka pemerintah telah menempuh berbagai kebijakan untuk meningkatkan produksi padi, yaitu dengan program intensifikasi, ekstensifikasi, diversifikasi dan rehabilitasi lahan pertanian. (Ir. Sutrisno, 2016)

\subsection{Debu}

Debu merupakan sebuah partikertikel pada kecil dengan diameter kurag dari 500 mikrometer. Di atmosfer bumi, debu berasal dari sejumlah sumber: loess yang disebarkan melalui angina, letusan gunug berapim pencemaran, dan lainnya. Debu dianggarp aerosol dan bisa memiliki tenaga radiasi local yang kuat di atmosfer dan berpengaruh pada iklim. (wikipedia, 2020) [7]

Dalam penelitian (Helmy, 2019) dengan judul "Hubungan Paparan Debu dan Karakteristik Individu dengan Status Faal Paru Pedagang di Sekitar Kawasan Industri Gresik" menjelaskan bahwa debu merupakan satu polutas udara yang memiliki tingkat toksisitas yang tinggi. Masyarakat pedagang kaki lima beresiko lebih besar terpapar zat pencemaran udara seperti debu, sehingga lebih rentan terkena gangguan kesehatan pada system pernapasan.

Debu merupakan partikel yang memiliki ukuran diameter $<10 \mu \mathrm{m}$ atau yang sering disebut particulate matter (PM10). Sensor yang dapat digunakan untuk mengukur debu adalah GP2Y1010AU0F. Sensor GP2Y1010AU0F adalah sensor debu yang memanfaatkan hamburan cahaya atau disebut dengan sistem penginderaan optik. Sensor ini dilengkapi dengan LED dan fotodioda yang diatur secara diagonal seperti yang pada berikut:

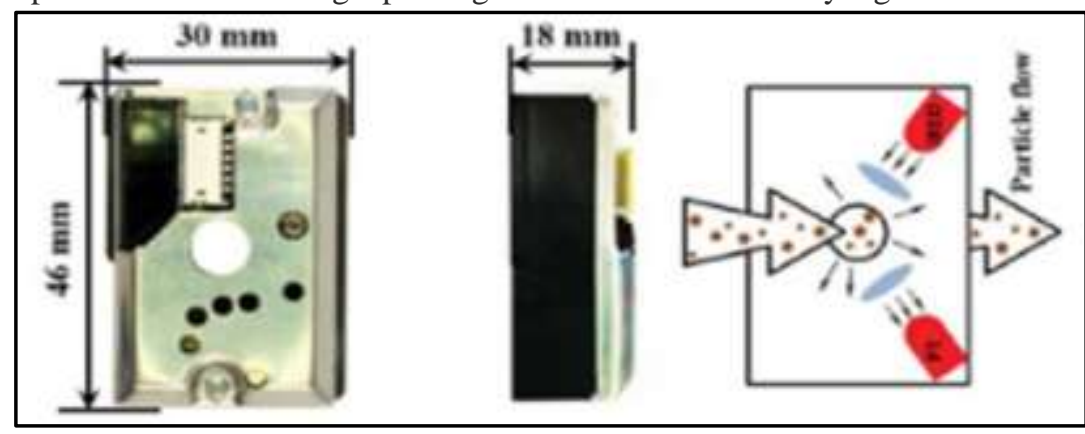
ditunjukkan Gambar

\subsection{Mikrokontroller}

Mikrokontroler adalah suatu chip berupa IC (Integrated Circuit) yang dapat menerima sinyal input, mengolahnya dan memberikan sinyal output sesuai dengan program yang diisikan ke dalamnya. Sinyal input mikrokontroler berasal dari sensor yang merupakan informasi dari lingkungan sedangkan sinyal output ditujukan kepada aktuator yang dapat memberikan efek ke lingkungan. Jadi secara sederhana mikrokontroler dapat diibaratkan sebagai otak dari suatu perangkat/produk yang mempu berinteraksi dengan lingkungan sekitarnya. Mikrokontroler pada dasarnya adalah komputer dalam satu chip, yang di dalamnya terdapat mikroprosesor, memori, jalur Input/Output (I/O) dan perangkat pelengkap lainnya. Kecepatan pengolahan data pada mikrokontroler lebih rendah jika dibandingkan dengan PC. [8]

Pada PC kecepatan mikroprosesor yang digunakan saat ini telah mencapai orde GHz, sedangkan kecepatan operasi mikrokontroler pada umumnya berkisar antara $1-16 \mathrm{MHz}$. Begitu juga kapasitas RAM dan ROM pada PC yang bisa mencapai orde Gbyte, dibandingkan dengan mikrokontroler yang hanya berkisar pada orde byte/Kbyte. Meskipun kecepatan pengolahan data dan kapasitas memori pada mikrokontroler jauh lebih kecil jika dibandingkan dengan komputer personal, namun kemampuan mikrokontroler sudah cukup untuk dapat digunakan pada banyak aplikasi terutama karena ukurannya yang kompak.

Mikrokontroler sering digunakan pada sistem yang tidak terlalu kompleks dan tidak memerlukan kemampuan komputasi yang tinggi. Sistem yang menggunakan mikrokontroler sering disebut sebagai embedded system atau dedicated system. Embeded system adalah sistem pengendali yang tertanam pada suatu produk, sedangkan dedicated system adalah sistem pengendali 67 yang dimaksudkan hanya untuk suatu fungsi tertentu. Sebagai contoh, printer adalah suatu embedded system karena di dalamnya terdapat mikrokontroler sebagai pengendali dan juga dedicated system karena fungsi pengendali tersebut berfungsi 
hanya untuk menerima data dan mencetaknya.

Hal ini berbeda dengan suatu PC yang dapat digunakan untuk berbagai macam keperluan, sehingga mikroprosesor pada PC sering disebut sebagai general purpose microprocessor (mikroprosesor serba guna). Pada PC berbagai macam software yang disimpan pada media penyimpanan dapat dijalankan, tidak seperti mikrokontroler hanya terdapat satu software aplikasi. Penggunaan mikrokontroler antara lain terdapat pada bidang-bidang berikut ini. 1. Otomotif : Engine Control Unit, Air Bag, fuel control, Antilock Braking System, sistem pengaman alarm, transmisi automatik, hiburan, pengkondisi udara, speedometer dan odometer, navigasi, suspensi aktif. 2. perlengkapan rumah tangga dan perkantoran : sistem pengaman alarm, remote control, mesin cuci, microwave, pengkondisi udara, timbangan digital, mesin foto kopi, printer, mouse. 3. pengendali peralatan di industri. 4. robotika.

Saat ini mikrokontroler 8 bit masih menjadi jenis mikrokontroler yang paling populer dan paling banyak digunakan. Maksud dari mikrokontroler 8 bit adalah data yang dapat diproses dalam satu waktu adalah 8 bit, jika data yang diproses lebih besar dari 8 bit maka akan dibagi menjadi beberapa bagian data yang masing-masing terdiri dari 8 bit. Masing-masing mikrokontroler mempunyai cara dan bahasa pemrograman yang berbeda, sehingga program untuk suatu jenis mikrokontroler tidak dapat dijalankan pada jenis mikrokontroler lain. (Wahyuni, 2015)

Dalam penelitian (Patil \& dkk, 2017) Dengan munculnya mikrokontroler dan mikroprosesor, pengembangan konverter dan kontrol elektronik daya teknologi telah melihat evolusi yang cukup besar. Sebelumnya, kekuasaan Konverter menggunakan kontrol analog karena kesederhanaannya dalam sirkuit dan biaya pengembangan rendah, tetapi bentuk gelombang output menderita dengan nilai THD tinggi bersama dengan dinamika yang lambat tanggapan. Chip tertanam modern memberikan kecepatan dan fleksibilitas bersama dengan solusi yang hemat biaya dan dengan demikian, miliki berhasil menggantikan rekan analog mereka.

\section{Sensor DHT11}

Sensor DHT11 adalah modul sensor yang berfungsi untuk mengukur objek suhu dan kelembaban dengan output data digital. Sensor ini dapat membaca dan mengukur suhu dan kelembaban lebih cepat dan responsif. Selain itu juga memiliki fitur kalibrasi nilai pembacaan suhu dan kelembaban yang kemudian disimpan pada memori program One Time-Programmable (OTP) atau disebut juga dengan [9]

\section{Analisis}

\subsection{Deskripsi Sistem}

system penentu Gudang beras dengan memonitor kondisi gudang beras menggunakan Arduino mega. Anatarmuka system dengan pengguna akan berbasis pralform web Things-Board. Dalam system ini akan dirancang dengan pengelompokkan ke dalam 2 bagian, yaitu server dan client.

Bagian server terdiri dari perangkat utama yaitu computer server dan perangkat Mikrokontroller Arduino mega dengan perangkat pendukungnya. Perangkat computer server berfungsi untuk menyimpan data sensor dan program web server. Program web server yang digunakan terdiri dari platform Things-Board yang berbasis Things-Board dan basis data Mysql. Konektivitas antara computer server dan Mikrokontroller Arduino Mega menggunakan Wifi Acces Point.

\subsection{Model Sistem}

\section{Sistem Requirement}

Data Mining

Pada tahapan ini, penulis menggunakan metode perangkingan Simple Addictive Weight (SAW) pada data numerk.

Interpretation/evaluation

Setelah proses perhitungan dari data mining didapatkan, pada tahapan ini juga dilakukan pemeriksaan apakah informasi yang didapatkan sesuai dengan fakta atau sama dengan penelitian sebelumnya.

Tabel Sampel data Gudang 1

\begin{tabular}{|c|c|c|c|}
\hline No. & Debu & Kelembaban & Suhu \\
\hline 1 & 0,100488 & 86 & 30 \\
\hline 2 & 0,109766 & 87 & 30 \\
\hline 3 & 0,1 & 87 & 30 \\
\hline 4 & 0,1 & 88 & 30 \\
\hline 5 & 0,1 & 88 & 30 \\
\hline 6 & 0,1 & 87 & 30 \\
\hline 7 & 0,1 & 87 & 30 \\
\hline 8 & 0,1 & 86 & 30 \\
\hline 9 & 0,1 & 86 & 30 \\
\hline
\end{tabular}




\begin{tabular}{|c|c|c|c|}
\hline 10 & 0,1 & 86 & 30 \\
\hline 11 & 0,123926 & 85 & 30 \\
\hline 12 & 0,1 & 85 & 30 \\
\hline 13 & 0,118555 & 86 & 30 \\
\hline No. & Debu & Kelembaban & Suhu \\
\hline 14 & 0,1 & 86 & 30 \\
\hline 15 & 0,12002 & 86 & 30 \\
\hline 16 & 0,1 & 86 & 30 \\
\hline 17 & 0,1 & 85 & 30 \\
\hline 18 & 0,1 & 86 & 30 \\
\hline 19 & 0,1 & 86 & 30 \\
\hline 20 & 0,1 & 86 & 30 \\
\hline
\end{tabular}

Tabel Sampel Data Gudang 2

\begin{tabular}{|c|c|c|c|}
\hline No. & Debu & Kelembaban & Suhu \\
\hline 1 & 0,599512 & 86 & 30 \\
\hline 2 & 0,599512 & 86 & 30 \\
\hline 3 & 0,598535 & 86 & 30 \\
\hline 4 & 0,599023 & 85 & 30 \\
\hline 5 & 0,599512 & 85 & 30 \\
\hline 6 & 0,599512 & 83 & 30 \\
\hline 7 & 0,599512 & 83 & 30 \\
\hline 8 & 0,599512 & 83 & 30 \\
\hline 9 & 0,599512 & 82 & 30 \\
\hline 10 & 0,599512 & 82 & 30 \\
\hline 11 & 0,599512 & 85 & 30 \\
\hline 12 & 0,599512 & 85 & 30 \\
\hline 13 & 0,599512 & 85 & 30 \\
\hline 14 & 0,599023 & 85 & 30 \\
\hline 15 & 0,599512 & 86 & 30 \\
\hline 16 & 0,599512 & 86 & 30 \\
\hline 17 & 0,599512 & 86 & 30 \\
\hline No. & Debu & Kelembaban & 30 \\
\hline 18 & 0,599512 & 86 & 30 \\
\hline 19 & 0,572656 & 80 & 81 \\
\hline 20 & 0,572168 & & Suhu \\
\hline
\end{tabular}


Tabel Data Penentuan Tempat Penyimpnan Beras

\begin{tabular}{|c|c|c|r|r|}
\hline \multirow{2}{*}{ No. } & \multirow{2}{*}{ Alternatif } & \multicolumn{3}{|c|}{ Kriteria } \\
\cline { 3 - 5 } & & C1 & \multicolumn{1}{c|}{ C2 } & \multicolumn{1}{c|}{ C3 } \\
\hline 1 & A1 & 0,103638 & 86,25 & 30 \\
\hline 2 & A2 & 0,596704 & 84,3 & 30 \\
\hline 3 & A3 & 0,532056 & 74,45 & 31 \\
\hline
\end{tabular}

Normalisasi Matriks dengan persamaan 1 adalah sebagai berikut:

Pada Alternatif A1 :

atau

$r 11=\frac{0.1036378}{\operatorname{Max}(0,1036378 ; 0,596704 ; 0,532056)}=0,1737$

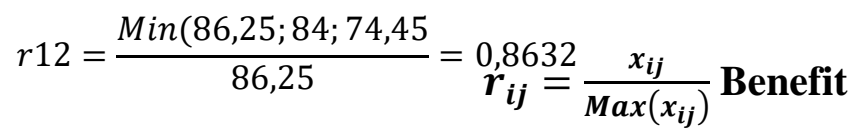

$r 13=\frac{30}{\operatorname{Max}(30 ; 30 ; 30)}=0,9677$

Pada Alternatif A2 :

$r 21=\frac{0,5967043}{\operatorname{Max}(0,1036338 ; 0,596704 ; 0,532056}=1,0000$

$r 22=\frac{\operatorname{Min}(86,25 ; 84,3 ; 74,45)}{84,3}=0 \boldsymbol{P}_{\boldsymbol{t}}^{832}$

$r 23=\frac{30}{\operatorname{Max}(30 ; 3 \overline{\sigma ; 30})}=0.9677_{i \boldsymbol{i}}$

Pada Alternatif A3 :

$r 31=\frac{0,5320558}{\operatorname{Max}(0,1036338 ; 0,596704 ; 0,532056)}=0,8917$

$r 32=\frac{\operatorname{Min}(86,25 ; 84,3 ; 74,45)}{74,45}=1,0000$

$r 33=\frac{31}{\operatorname{Max}(30 ; 30 ; 31)}=1,0000$

Mencari Alternative menggunakan persamaan 2 dengan Rumus sebagai berikut :

$V 1=(0,4 \times 0,1737)+(0,3 \times 1,0000)+(0,3 \times 0,9677)=0,6188$

$V 2=(0,4 \times 1,0000)+(0,3 \times 0,9774)+(0,2 \times 0,9667)=0,9553$

$V 3=(0,4 \times 0,8917)+(0,3 \times 0,8632)+(0,3 \times 1,0000)=0,9567$

Tabel 3. 1 Hasil Perangkingan

\begin{tabular}{|c|c|c|}
\hline \multicolumn{1}{|c|}{ Nama Alternatif } & Nilai & Rangking \\
\hline Gudang 3 & 0,9567 & 1 \\
\hline Gudang 2 & 0,9553 & 2 \\
\hline Gudang 1 & 0,6188 & 3 \\
\hline
\end{tabular}

Dari tabel 3.7 dapat disimpulkan bahwa hasil dari perhitungan tersebut memperoleh hasil perangkingan dengan beberapa kriteria dari setiap parameter yang ada, yang nantinya akan menjadi sebuah pembersihan real-time tempat penyimpanan beras tanpa harus terpacu pada jadwal pembersihan, dan melibatkan banyak petugas. 


\subsection{Model Sistem}

\section{Sistem Requirement}

Software requirement merupakan suatu statement yang menjerlaskan tentang berbagai kebutuhan yang harus terpenuhi oleh suatu software. Software requirement dibuat atas dasar hasil proes analisis agar mempermudah proses pengembangan perangkat lunak. Berikut adalah software requirement hasil analisis penulis :

1. Sistem ini untuk membaca data dan parameter.

2. Sensor Debu dapat mendeteksi ketebalan debu.

3. Sensor DHT11 dapat membaca suhu dan kelembaban.

4. Modul Wifi ESP8266 dapat membaca data kemudian disimpan kecloud.

5. Data dapat disimpan dan ditampilkan di cloud melalui platform yang digunakan.

6. Data dapat disimpan dan ditampilakn dicloud melalui paltforn yang digunakan.

7. Data dicloud dapat di export dalam bentuk excel.

8. Sistem ini dapat menyimpan data di database yang terkoneksi melalui web.

9. Sistem ini dapat melakukan analisis data dengan metode Simple Addictive Weight(SAW).

10. WEB memungkinkan dapat melakukan pangujian data parameter dengan metode Simple Addictive Weight(SAW).

11. Admin dapat melakukan login ke system untuk mengelola system agar dapat berjalan.

12. Admin dapat melakukan edit dan hapus data uji parameter yang telah di inputkan.

\section{Use Case Diagram}

Diagram Use Case menggambarkan actor, usecase dan relasinya sebagai suatu urutan atau tindakan yang memberikan nilai trukur untuk actor. Sebuah use case dapat digambarkan sebagai elips horizontal dalam suatu diagram UML Usecase.

\section{Activity Diagram}

Menggambarkan aktifitas-aktifitas, objek, state, transisi state dan event. Dengan kata lain kegiatan diagram alur kerja menggambarkan perilaku system untuk aktivitas. Activity diagram menggambarkan berbagai alur aktivitas dalam system yang sedang dirancang, bagaimana masing-masing alir berawal, dan bagaimana mereka berakhir. Berikut beberapa aktivitas system yang digambarkan dengan activity diagram.

1. Activity diagram Sensor DHT11

Pada activity diagram Sensor DHT11 merupakan aktivitas sebagai penyedia parameter. Pada tahapan awal menampilkan halaman utama , membuat script dan menampilkan hasil pada serial monitor, mengupload hasil script sensor yang telah di program jika berhasil dapat melihat hasil kerja sensor saat membaca data dan jika ada script yang tidak sesuai harus memperbaiki script yang keliru.

2. Activity diagram Sensor Debu

Pada activity diagram Sensor Debu merupakan aktivitas sebagai penyedia parameter. Pada tahapan awal menampilkan halaman utama, membuat script dan menampilkan hasil pada serial monitor, mengupload hasil script sensor yang telah di program jika berhasil dapat melihat hasil kerja sensor saat membaca data dan jika ada script yang tidak sesuai harus memperbaiki script yang keliru.

3. Activity Diagram Login Platform Things-board

Activity diagram login adalah sebagai identitas awal sebelum masuk pada system informasi Platform ThingsBoard.

4. Activity Diagram Manage Things-board

Pada activity diagram manage things-board merupakan aktivitas-aktivitas yang dapat dilakukan platform things-board. Pada platform things-board harus membuat beberapa device untuk mendapatkan suatu data yang di baca oleh sensor.

5. Activity diagram database

Activity diagram database proses pembuatan database menggunakan MySQL. Database ini digunakan untuk menyimpan data yang diterima dari platfform thingspeak kemudian di analisis oleh sistem yang sudah diimplementasikan metode SAW.

Activity diagram analisis ini mengolah data parameter untuk mendapatkan keputusan Gudang terbaik dari nilai data parameter yang diinputkan sebelumnya. Untuk penentu keputusannya menggunakan metode Perangkingan SAW yang sudah diimplementasikan pada sistem.

Robusteness Diagram

Robustness diagram merupakan alat untuk menjembatani adanya ruang kosong dari analisis desain yang sebenarnya terhadap implementasi. Analisis dilakukan dengan membuat robustness diagram yang menghubungkan antara analisis dan desain. Ada 3 stereotype robustness diagram dianataranya, boundary object, entity object, dan controller object.

Robustness Diagram Mikrokontroller

Pada robustness diagram mikrokontroller ini menjelaskan desain alur kerja mikrokontroller. Pada tahap awal akan dilakukan configurasi di arduino IDE dengan mengatur source code untuk di upload ke 
board arduino kemudian arduino akan melakukan perintah sesuai source code yang telah di configurasikan. Lalu arduino akan membaca data dengan sensor yang telah terkoneksi dengan arduino. Robustness Diagram Platform

Pada robustness diagram platform ini menjelaskan desain alur kerja platform. Paltform ini berfungsi menampilkan data dari mikrokontroller dan menyimpan data di cloud. Platform juga dapat mengexsport data menjadi file menjadi dokumen excel.

Robustness Diagram User

Pada robustness diagram user log in ke platform kemudian user dapat melakukan export data yang telah di simpan di platform.

Robustness Diagram Database

Robustness diagram database proses pembuatan database menggunakan MySQL. Database ini digunakan untuk menyimpan data yang diterima dari platfform thingspeak kemudian di analisis dan ditampilkan di sistem.

\subsection{Struktur tabel}

Dalam perancangan basis data pada penelitian ini terdiri dari 5 tabel yaitu, tabel gudang, sensor, tb_bobot, tb_nilai, tb_nilai. Berikut adalah struktur dari tabel-tabel tersebut :

1. Tabel gudang

Tabel 3. 2 Struktur tabel gudang

\begin{tabular}{|l|l|l|l|}
\hline No. & attribute & Type Data & Keterangan \\
\hline 1 & kd_gudang & varchar(20) & PK \\
\hline 2 & nama & varchar(35) & \\
\hline 3 & kapasitas & varchar(50) & \\
\hline 4 & petugas & varchar(35) & \\
\hline
\end{tabular}

2. Tabel Sensor

Tabel 3. 3 struktur tabel sensor

\begin{tabular}{|l|l|l|l|}
\hline No. & Attribute & Type Data & Keterangan \\
\hline 1 & id & Int(20) & PK \\
\hline 2 & kd_gudang & varchar(11) & \\
\hline 3 & debu & double(9) & \\
\hline 4 & kelambaban & double & \\
\hline & suhu & double & \\
\hline
\end{tabular}

Tabel tb_bobot

Tabel 3.5 struktur tabel tb_bobot

\begin{tabular}{|l|l|l|l|}
\hline No. & Attribute & Type Data & Keterangan \\
\hline 1 & B_debu & double & \\
\hline 2 & B_kelembaban & double & \\
\hline 3 & B_suhu & double & \\
\hline
\end{tabular}

3. Tabel $t b \_h a s i l$

Tabel 3. 4 struktur tabel hasil

\begin{tabular}{|c|l|l|l|}
\hline No. & Attribute & Type Data & Keterangan \\
\hline 1 & id & Int(11) & PK \\
\hline 2 & gudang & varchar(100) & \\
\hline 3 & debu & double & \\
\hline 4 & kelembaban & double & \\
\hline 5 & suhu & double & \\
\hline 6 & total & double & \\
\hline
\end{tabular}

4. Tabel tb_nilai

Tabel 3. 5 struktur tabel tb_nilai

\begin{tabular}{|l|l|l|l|}
\hline No. & Attribute & Type Data & Keterangan \\
\hline 1 & kd_gudang & $\operatorname{varchar}(20)$ & PK \\
\hline
\end{tabular}




\begin{tabular}{|l|l|l|l|}
\hline 2 & nama & varchar(35) & \\
\hline 3 & debu & double & \\
\hline 4 & kelembaban & double & \\
\hline 5 & suhu & double & \\
\hline
\end{tabular}

Perancangan antarmuka

Software interfaces merupakan visualisasi perancangan tampilan perangkan lunak yang akan dibangun untuk memastikan bagaimana seorang petugas ataupun user berinteraksi dengan aplikasi tersebut dan mendapatkan informasi yang ditampilkan pada layar. Terdapat 8 rancangan antarmuka pada Aplikasi system Penentu Gudang Beras Berbasis IoT menggunakan metode SAW pada Platform Things-board.

Halaman Utama

Berikut adalah rancangan halaman utama pada aplikasi system Sistem penentu gudang beras berbasis IoT menggunakan metode SAW

\section{4. mentasi}

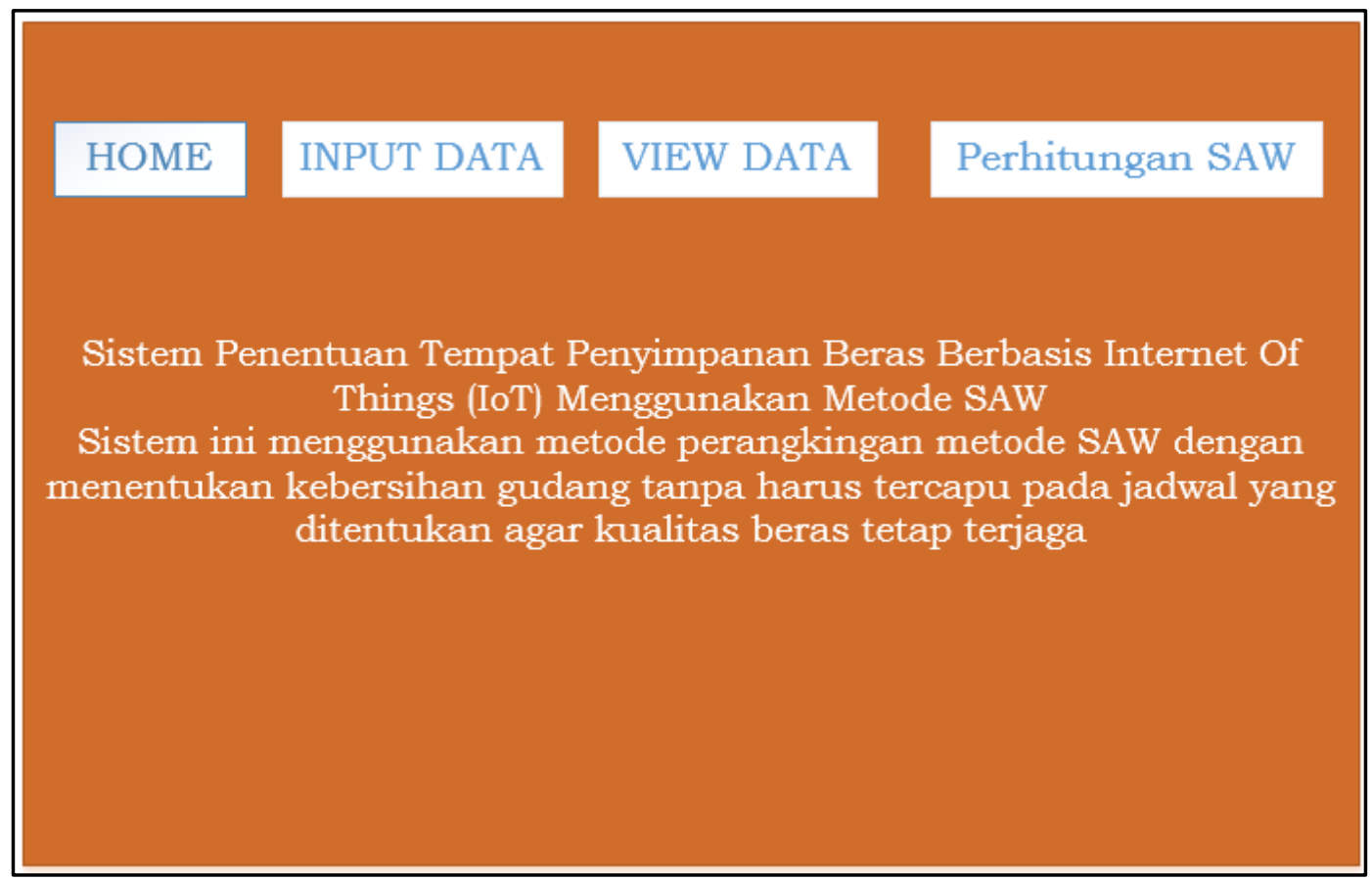

\subsection{Implementasi Basis Data}

Dalam merancang dan mengembangkan Sistem yang penulis buat, penulis menggunakan MySQL sebagai basis data untuk perangkat lunak ini. Aplikasi yang digunakan adalah Xampp v3.2.2 berikut ini akan dipaparkan secara jelas pembuatan sistem basis data untuk sistem yang penulis buat ini, sebagai berikut :

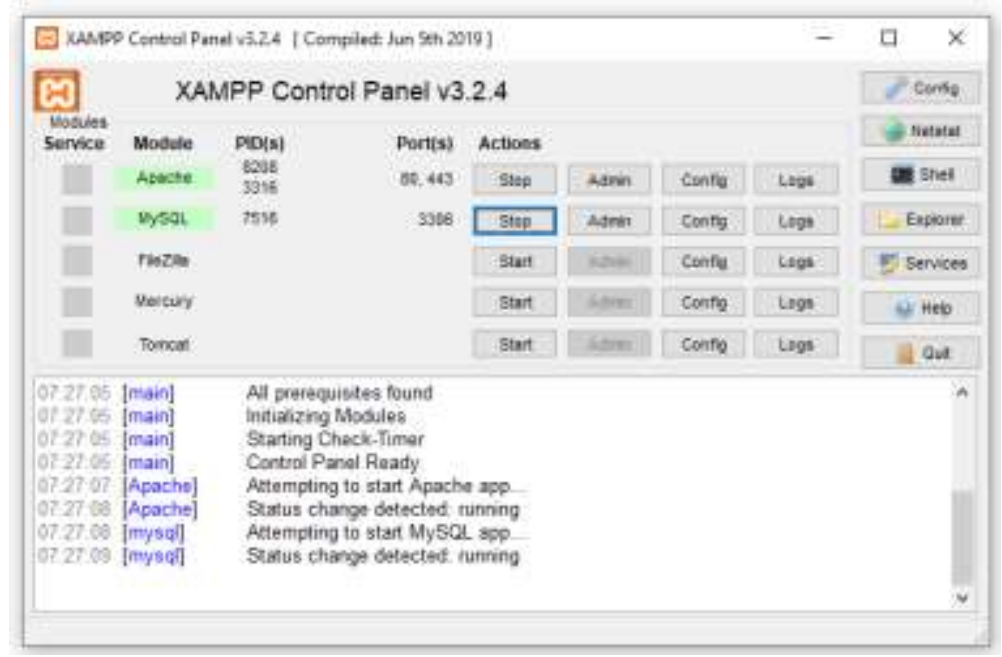


Langkah pertama yang harus dilakukan adalah mengaktifkan aplikasi xampp seperti yang ditunjukan gambar di bawah ini yaitu Apache dan MySQL :

Pada tampilan xampp ini klik start pada apache sama mysql untuk dapat membuka phpMyAdmin pada browser.

Setelah aplikasi xampp di aktifkan maka buka browser masuk ke localhost/phpmyadmin seperti yang ditunjukan gambar di bawah ini

Setelah masuk ke phpMyAdmin, silahkan klik new untuk buat basis data atau bisa dilihat pada gambar 4 . 10.

Setelah pembuatan database maka langkah selanjutnya adalah pembuatan tabel, dimana tabel dalam perangkat lunak ini adalah gudang, hasil, kriteria, kualitas, model, nilai, pengguna, penilaian.

\subsection{Implementasi Antarmuka Platform}

Antarmuka platform thingsboard digunakan untuk menampilkan dan menyimpan data yang dikirim oleh mikrokontroler, selain itu untuk thingsboard akan bekerja selama koneksi internet dengan baik. Di platform thingsboard harus membuat device sebagai langkah awal projek dimulai dan melakukan modifikasi sesuai dengan projek yang akan di buat. Dalam satu akun thingsbboard dapat membuat beberapa device sehingga cocok memuat projek yang banyak

thingsboard yang sudah menerima data kemudian disajikan kedalam bentuk grafik ataupun hanya tampilan data dari setiap parameternya. Data akan terus ditampilkan selama mikrokontroler dijalankan dan thingsboard terkoneki internet. Data yang ditampilkan secara otomatis sudah disimpan dalam device tersebut dan dapat diexport data kedalam bentuk dokumen jenis excel dengan ekstensi csv.

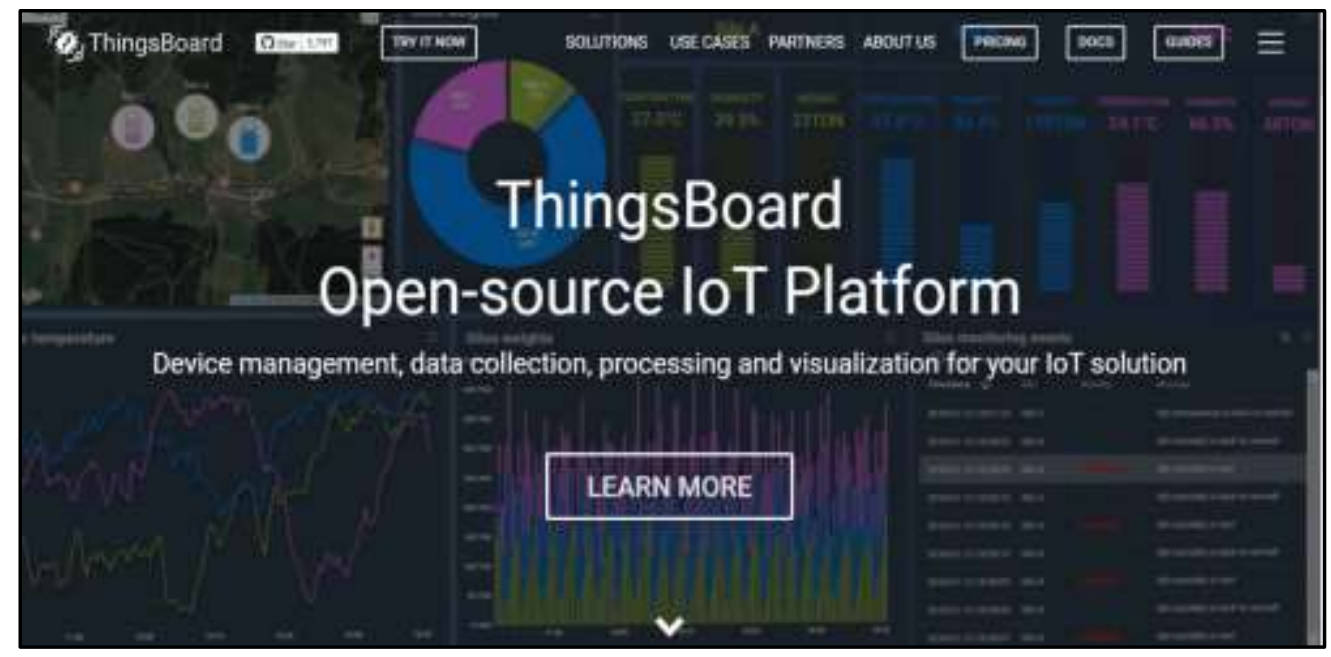

\subsection{Implementasi Antarmuka Sistem}

Untuk melihat tampilan antarmuka system perhitungan Perangkingan dengan Metode SAW yaitu pertama kita buka aplikasi xampp, setelah itu klik star apache dan mysql untuk menghubungkan ke system tersebut. Kedua buka aplikasi browser lalu ketikan address bar "localhost/Metode/saw 5/spk-saw-master" maka akan muncul seperti pada Gambar 4.15 sebagai berikut:

Pada halaman input data gudang ini yaitu, user akan menginputkan kode gudang dengan kode yang berbeda sebagai primary key, nama gudang lokasi atau tempat yang berbeda, kapasitas gudang di dalam ruangan tersebut, petugas yang saat itu hendak bertugas membersihkan gudang. 
Pada halaman input data nilai (parameter) ini berfungsi untuk memberikan nilai pada setiap parameter yang telah ditentukan pada hitungan manual sebelumnya yang nantinya di proses oleh system. Halaman ini terdapat kode gudang yang sebelumnya telah di inputkan pada form Input data Gudang, selanjutnya nama gudang yang akan di pantau yaitu Gudang 1, Gudang 2, dan Gudang 3. Nilai suhu, yang telah didapatkan saat penilitian dan telah di hitung manual melalui Aplikasi Microssoft Excel menjadi hasil akhir dengan sampel data sebanyak 20 per gudang yaitu, Gudang $1=0.695$, Gudang $2=0.1737$, Gudang 3 $=0.3567$. Nilai kelembaban Gudang $1=0.2590$, Gudang $2=0.2649$, Gudang $3=0.3000$ dan Nilai Debu Gudang $1=0.2903$, Gudang $2=0.2903$, Gudang $3=0.3000$. halaman ini berisikan form bobot nilai persentase yang telah ditentukan berdasarkan tingkat pengaruh dari parameter yang ada, dari parameter suhu berbobot $0.3 \%$, parameter Kelembaban berbobot $0.3 \%$, dan parameter Debu berbobot $0.4 \%$. Gambar 4.18 Halaman Bobot Parameter, yaitu:

Halaman ini berfungsi untuk melihat hasil input data gudang yang telah di inputkan pada form data gudang, apakah data tersebut sudah sesuai dengan identitas yang ada atau belum. Pada halaman ini dilengkapi dengan menu edit dan hapus untuk memastikan sinkronisasi data yang ada di lapangan. Halaman ini menampilkan Kode Gudang, Nama Gudang, Kapasitas, Petugas, dan Aksi

Halaman ini berfungsi untuk melihat hasil input data nilai (parameter) yang telah di inputkan pada form input data nilai (parameter), apakah data tersebut sudah sesuai dengan identitas yang ada atau belum. Pada halaman ini dilengkapi dengan menu edit dan hapus untuk memastikan sinkronisasi data yang ada di lapangan. Halaman ini menampilkan Kode Gudang, parameter suhu, parameter kelembaban, parameter debu, dan aksi.

Halaman ini berfungsi untuk melihat hasil input data bobot yang telah di inputkan pada form input data bobot, apakah data tersebut sudah sesuai dengan identitas yang ada atau belum. Pada halaman ini dilengkapi dengan menu edit dan hapus untuk memastikan sinkronisasi data yang ada di lapangan. Halaman ini menampilkan parameter suhu, parameter kelembaban, parameter debu, dan aksi. Gambar 4.21 Halaman view data bobot, yaitu;

Halaman ini berisi kode gudang, parameter suhu, parameter kelembaban, dan parameter debu yang

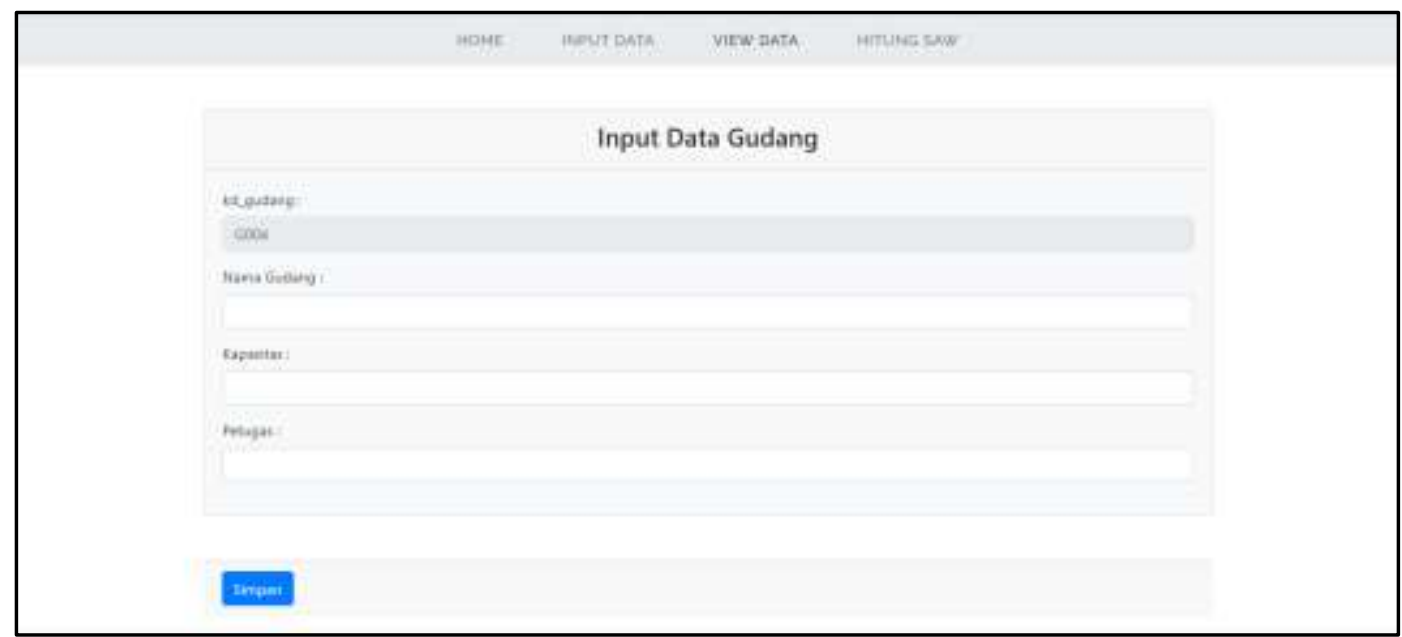

berupa matriks keputusan. Nantinya akan diakumulasikan dengan total semua gudang yang ada dengan masing-masing parameter. Parameter Suhu dengan rumus (Max) Benefit, parameter Kelembaban dengan rumus (Min) Benefit, dan parameter debu dengan rumus (Max) Benefit. Gambar 4.22 Halaman Hitung SAW (Matriks Keputusan) sebagai berikut;

Pada halaman ini berfungsi sebagai fungsi bobot yang dikalikan dengan hasil dari normalisasi matriks X ij dari hasil penjumlahan setiap gudang 1, gudang 2, dan gudang 3 pada halaman matriks keputusan. Pada halaman ini menampilkan parameter suhu, parameter kelembaban, dan parameter debu.

Halaman ini menampilkan proses normalisasi penghitungan dari metode SAW, dengan beberapa data yang telah di inputkan dari form sebelumnya. Pada halaman ini akan menghitung otomatis oleh system yang telah di program sebelumnya sesuai dengan rumus metode yang di tentukan. Pada halaman ini berisi Matriks keputusan, Nilai Max dari penjumlahan setiap gudang, dan nilai max dari semua hasil gudang yang telah di proses dari hasil normalisasi benefit MAX dan MIN dari masing-masing keriteria. 
Halaman ini menampilkan hasil keputusan dari perangkingan semua data parameter yang masuk. Parameter suhu, kelembaban, dan parameter debu. Dengan rumus yang telah di program pada system, maka diperoleh hasil perangkingan gudang atau tempat penyimpanan dengan suhu yang max, kelembaban min, dan debu max. Maka diperoleh hasil 1.0474903474903 untuk gudang 3, 0.83998979404732 untuk gudang 2, dan 0.7455191477432 untuk gudang 1.

Maka dapat disimpulkan untuk hasil data tersebut bahwa gudang 1 berada di urutan ke 3, gudang 2 berada di urutan ke 2, dan gudang 3 berada di urutan ke 1 .

\subsection{Implementasi Hasil Pengujian Alat}

Tabel hasil pengujian alat merupakan record sistem untuk menguji apakah alat yang penulis buat berjalan dengan baik tanpa error atau tidak.

Tabel 4. 1 Tabel hasil pengujian alat

\begin{tabular}{|c|l|c|}
\hline No. & \multicolumn{1}{|c|}{ Nama Proses } & Hasil Pengujian \\
\hline 1 & Koneksi nodemcu ke wifi & Ya \\
\hline 2 & Koneksi $p c$ (personal computer) ke wifi & Ya \\
\hline 3 & Koneksi nodemcu ke $p c$ (personal computer) & Ya \\
\hline 2 & Pengambilan data Seuhu & Ya \\
\hline 3 & Pengambilan data Kelembaban & Ya \\
\hline 4 & Pengambilan data Debu & Ya \\
\hline 4 & Monitoring data dari sensor & Ya \\
\hline
\end{tabular}

\section{Kesimpulan}

1. Optimalnya monitoring system penentuan tempat penyimpanan beras dengan tidak terpacu pada suhu dan kelembaban pada tempat penyimpanan beras di lokasi tersebut.

2. Melihat dari penelitian terkait sebelumnya, penulis berinisiatif dengan membersihkan tempat penyimpanan beras dengan hasil data sensor debu hasil terbanyak.

3. Dengan adanya system ini, kualitas beras dan ketahanan beras terhindar dari jamur dan kutu dapat bertahan lebih lama.

\section{Saran}

Saran untuk mengembangkan sistem ini antara lain:

1. Diharapkan dipenelitian selanjutnya bisa mencakup banyak parameter yang lebih luas untuk dapat menentukan gudang beras dengan cepat.

2. Diharapkan penelitian selanjutnya alat yang di buat lebih banyak dan dapat mendeteksi tempat penyimpanan dengan waktu yang bersamaan.

3. Sistem Penentuan Gudang Beras berbasis IoT (Internet Of Things) Menggunakan Metode SAW Pada Platform Thingsboard dapat di akses menggunakan handphone agar admin mudah mengklarisfikasikan

\section{Daftar Pustaka}

[1] Abilovani, d. (2018). Implementasi Protokol MQTT Untuk Sistem Monitoring Perangkat IoT. Jurnal Pengembangan Teknologi Informasi dan Ilmu Komputer Vol. 2, No. 12.

[2] Aghenta, d. (2019). Design and implementasi of a low-cost, open source IoT-based SCADA system using ESP32 with OLED, ThingsBoard adn MQTT protocol.

[3] . Yusuf, \& dkk. (2017). Analisis pergudangan di bagian gudang barang jadu (finish goods) pt Nipress TBK Cileungsi Bogor. Jurnal Manajemen Industri dan Logistik

[4] Ardiansyah, \& dkk. (2018). Sistem Monitoring Debu dan Karbon Monoksida Pada Lingkungan Kerja Boiler di PT. Karunia Alam Segar. Jurnal IKRA-ITH Teknologi Vol 2 No 3.

[5] wikipedia. (2020, Juni 01). Retrieved from https://id.wikipedia.org/wiki/Debu

[6] System Espressif. (2018). This document provides the specifications of ESP32 family of chips

[7] A. Junaidi, "Internet Of Things, Sejarah, Teknologi Dan Penerapannya : Review," Jurnal Ilmiah Teknologi Informasi Terapan Volume I, No 3,62-66, 2015.

[8] Irwansyah, "Penggunaan Metode Weighting Product (WP) Pada Sistem Pendukung Keputusan Dalam Penentuan Barang Konveksi," Just TI Volume 7 No 2, 889-896, 2015.

[9] S. Lestari, "Penerapan Metode Weighted Product Model Untuk Seleksi Calon Karyawan,” Jurnal Sistem Informasi (JSI), VOL. 5, NO. 1, 540-545, 2013.

[10] Basri, "Metode Weightd Product (WP) Dalam Sistempendukung Keputusan Penerimaan Beasiswa Prestasi," Jurnal Insypro (Information System and Processing), vol. 2, no. 1, 2017. 
[11] A. Ahmadi, and D. T. Wiyanti, Implementasi Weighted Product (WP) dalam Penentuan Penerima Bantuan Langsung Masyarakat PNPM Mandiri Perdesaan. Seminar Nasional Aplikasi Teknologi Informasi (SNATI), 19-22, 2014.

[12] A. E. Wijaya and H. Nurjaman, "IMPLEMENTASI METODE WEIGHTED PRODUCT DALAM MEMONITOR GUDANG PENYIMPANAN ROTI BERBASIS INTERNET OF THING PADA PLATFORM NODE-RED”, JTIK, vol. 13, no. 1, pp. 1-15, Apr. 2020

[13] A. Riska, Mengenal Arduino Software IDE, March 16, 2016. Accessed on: July 6, 2019. [Online]. Available: https://www.sinauarduino.com/artikel/mengenal-arduino-software-ide/

[14] M. Thakur, NodeMCU ESP8266 Communication Methods and Protocols: Programming with Arduino IDE. Amazon Digital Services LLC, 2018.

[15] IoT4Beginners, What is Node-RED?, Accessed on: July 17, 2019. [Online]. Available:https://iot4beginners.com/what-is-node-red/

[16] G. S. Barbieri, Flow-Based Programming Applied to IoT Development, OpenIoT \& ELC Europe2, 2016. Access on: 12 July, $2019 . \quad$ [Online]. Available:http://events.linuxfoundation.org/sites/events/files/slides/openiot2016Flow\%20Based\%20Programming\%20Applied\%20t o\%20IoT\%20Development.pdf 